\title{
Nudos críticos, paradojas y hegemonía en la formación del Estado en América Latina
}

\section{Critical nodes, paradoxes and hegemony in the configuration of the State in Latin America}

\section{Nódulos cruciais, paradoxos e hegemonia na formação do Estado na América Latina}

\author{
Jorge Daniel Vásquez-Arreaga \\ Universidad Central del Ecuador \\ Investigador Asociado a FLACSO \\ Recibido 08/10/2014 • Aprobado 10/10/2014 \\ DOI: http://dx.doi.org/10.15359/tdna.31-57.4
}

\section{Resumen}

Este artículo analiza la formación del Estado nacional en América Latina a partir de la revisión de trabajos que, desde la sociología histórica, recorren la configuración del terreno económico y político en el transcurso del siglo XIX y parte del XX. Parte de las lecturas y discusiones mantenidas en el seminario Formación de los Estados Nacionales en América Latina, dirigido por la historiadora Valeria Coronel de la Facultad Latinoamericana de Ciencias Sociales (FLACSO, Ecuador), plantearon una clave de lectura con base en las posibles vías de conformación

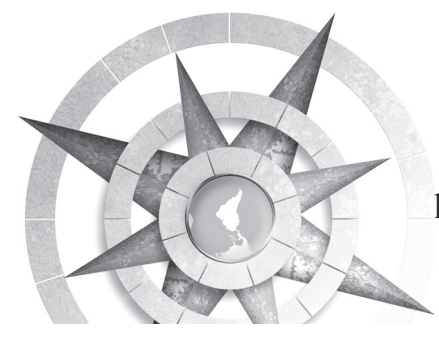

de los Estados en el horizonte de la hegemonía, en sentido gramsciano, con el propósito de identificar las consecuencias que la construcción de liderazgos tuvo en la configuración de los Estados modernos.

Palabras claves: América Latina, Estados nacionales en América Latina, hegemonía, sociología histórica, Temas de Nuestra América

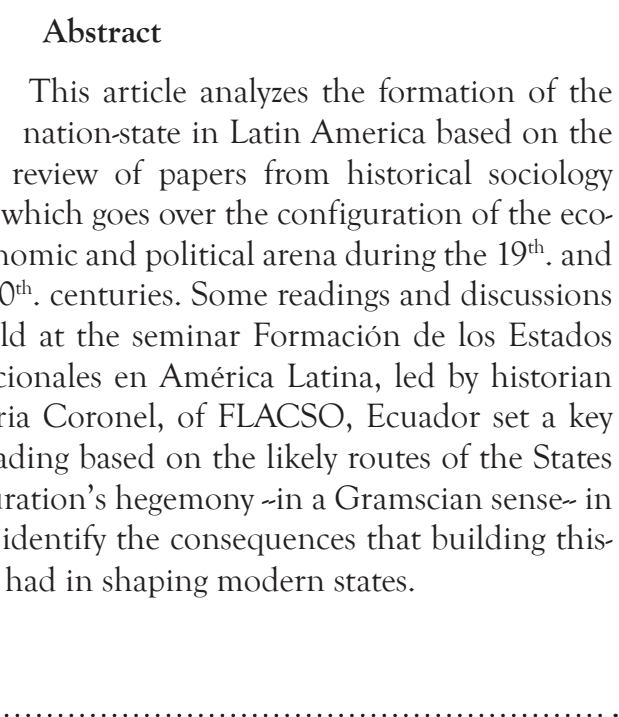


Keywords: Latin America, Latin American National-States, Hegemony, Historical Sociology, Temas de Nuestra América

\section{Resumo}

O objetivo deste artigo é analisar a formação do Estado-nacional na América Latina com base em uma revisão de trabalhos da sociologia histórica que fazem o escrutínio na cena econômica e política durante o século XIX e parte XX. Parte das leituras e discussões do seminário Formação dos Estados Nacionais na América Latina, liderado pela historiadora Valeria Coronel da Faculdade Latino-Americana de Ciências Sociais (FLACSO, Equador), suscitou uma chave de leitura com base nas prováveis vias de formação dos Estados no horizonte da hegemonia, em no sentido gramsciano. Issto a fim de identificar as consequências que a construção de liderança teve em moldar os Estados modernos.

Palavras-chave: América Latina, Estado-nação na América Latina, hegemonia, sociologia histórica, Temas de Nuestra América

\section{Introducción}

En este estudio se recurre, en un primer momento, a los análisis de Sempart Assadourian (1973) y William Roseberry (1993) en relación a la heterogeneidad estructural; para luego, a partir de los casos de Ecuador (Guerrero, 1991) y Cuba (Scott, 1985), identificar los nudos críticos de los conflictos enmarcados en las transformaciones de la economía y la estructura social en la Colonia.
Partiendo de una valoración de los aportes del debate de la sociología latinoamericana de los años setenta, se justifica la especificidad de los contextos coloniales latinoamericanos como escenarios de las transformaciones sociales que impulsaron la formación del Estado.

En un segundo momento se trata específicamente el nudo relacionado con el marco político republicano y el discurso liberal, resaltando las paradojas que, como resultado de la disputa entre varios sectores sociales, dan cuenta de la complejidad de la formación del Estado. De este modo, con base en los trabajos de López-Alves (2003) y Thurner (1997), se enfatizan las mediaciones institucionales del conflicto político entre grupos subalternos y élites emergentes, así como los capitales en juego a la hora de articular lo popular en el proyecto de Estado.

Finalmente, retomando los trabajos de Florence Mallon (2002) y de Alan Knight (2002 y 2005) para México, y el de Turits (2003) para el caso de República Dominicana, se plantea una clave de lectura basada en las posibles vías de conformación de los Estados en el horizonte de la hegemonía, en sentido gramsciano, con el propósito de identificar las consecuencias que la construcción de liderazgos tuvo en la configuración de los Estados modernos.

\section{Nudos críticos, paradojas y hegemonía... Jorge Daniel Vásquez-Arreaga}


Nudos críticos sobre la formación del Estado en América Latina

Realizar un balance sobre las transformaciones sociales que derivaron de la formación de los Estados nacionales en América Latina implica reconocer al menos dos niveles críticos que, desde diversos análisis sociohistóricos, permitan, en un primer momento, enmarcar la reflexión desde el campo de los paradigmas explicativos de las transiciones en la organización de las sociedades latinoamericanas, para luego atender la explicación de algunos procesos concretos que den cuenta de los nudos críticos de tales transformaciones.

En el primer sentido, la formación de los Estados nacionales tiene como marco la configuración de un modo de producción colonial en los términos que Sempat Assadourian (1973) planteó, es decir, a partir del cuestionamiento de la dicotomía de feudalismo/capitalismo como categorías omniabarcantes de las heterogéneas realidades coloniales. De este modo, Sempat Assadourian cuestionó la Teoría de la dependencia, que, desde fórmulas basadas en las contradicciones internas del capitalismo, pretende analizar la problemática del subdesarrollo en América Latina. El autor basó sus ideas en el análisis del texto Capitalismo y Subdesarrollo en América
Latina de Andre Gunter Frank (1965), sobre el cual reconoció que

Con sus tesis acerca de la invariabilidad estructural del capitalismo y del subdesarrollo, atacaba simultáneamente a dos frentes, dos proyectos políticos. La tesis de que era posible superar el subdesarrollo dentro del sistema capitalista mundial y la tesis de la izquierda tradicional que proponía un camino de liberación teniendo como acompañante una pretendida «burguesía nacional» (Sempat, 1973, p. 48).

Sempat Assadourian también señaló las limitaciones de las tesis de Frank, puesto que caen en una lectura homogeneizadora de la realidad que pretende analizar y cuestionar los alcances de las formulaciones de André Gunter Frank (cuyo análisis se circunscribe a la teoría de la dependencia) con relación a la condición de categoría explicativa que les confirió a:

1. La contradicción de la expropiación-apropiación del excedente económico (por el que el excedente dentro del espacio subdesarrollado desemboca en el espacio desarrollado),

2. la contradicción de la polarización metrópoli-satélite (por el cual se identifican los dos polos en una relación de dependencia) y 
3. la contradicción de la continuidad en el cambio (por la cual, a pesar de las transformaciones históricas, el capitalismo mantiene su estructura).

La crítica radical de Sempat Assadourian apunta al carácter invisibilizador del pensamiento de Frank, en tanto este pasa por alto el análisis de las dinámicas históricas en las sociedades subdesarrolladas. Así, Sempat Assadourian (1973) planteó que Frank relegaba el dinamismo específico de los fenómenos y vaciaba de sustancia y de historia una realidad mucho más rica y compleja, cuando de lo que se trata es de recurrir a herramientas que permitirían perforar las apariencias y la mitificación del sistema capitalista. Es decir, en última instancia, lo que se trata de plantear es que:

El conocimiento y manejo de tales mecanismos [aquellos por los que se transfiere el excedente] permitirían hacer visible las funciones y posición de los distintos tipos de capital que comandan, durante cuatro siglos, el proceso económico y localizar con exactitud los espacios externos e internos dominantes, al tiempo que se revelarían los fenómenos de dominación que caracterizan la relación entre los grupos sociales productivos (Sempat, 1973, p. 54).

Lo anterior nos ubica de lleno en la teoría de los modos de producción, que busca, a partir de la especificidad histórica de las formaciones económicas-sociales, medidas a partir de las dimensiones espaciales en las que se produce la circulación de mercancías (Sempat, 1973). Es decir, las formulaciones abstractas, que conciben el feudalismo como un sistema de producción para el uso (economía cerrada) o, en contraposición, conciben el capitalismo como sistema de producción para el mercado (economía abierta), resultan insuficientes cuando se pretende explicar la realidad de cualquier tiempo, puesto que para la comprensión de las sociedades coloniales es preciso construir un análisis de su heterogeneidad estructural.

Lo anterior coincide con la crítica que William Roseberry (1993) realizó de la lectura que durante la década de los sesenta se realizó en torno a los conflictos agrarios. Así, el supuesto de que la estructura básica de la propiedad de la tierra era similar en toda América Latina, junto al que sostiene que la estructura agraria básica no salía de la dualidad latifundio-minifundio, se ubica lejos del necesario abordaje de las caracterizaciones históricas de los regímenes de tierras y la diversidad de formas de propiedad que coexistían en la época; es decir, su heterogeneidad estructural.

Esta crítica de Roseberry se inscribe en un análisis más detallado de las 
diferentes posturas explicativas de las transformaciones agrarias en América Latina. Su lectura va desde las corrientes teóricas que han abordado la cuestión agraria (desarrollistas, marxistas, teóricos de la dependencia, analistas de clase, analistas de los modos de producción) hasta la crítica a los modelos sociológicos que se aplican desde la academia norteamericana. Para el autor estos últimos están desconectados de los procesos reales de transformación, por lo que es necesario valerse de los estudios de antropólogos e historiadores que se centran en el análisis de las específicas formas de producción y articulación de las relaciones respectivas al campesinado en la «hacienda colonial».

A este nivel, la evaluación de los nudos críticos fundamentales para la formación de los Estados nacionales pasa por el giro interpretativo que la Teoría de los modos de producción desarrolla sobre el análisis de la desigualdad y la supuesta autonomía de la economía con respecto a la política.

Así las cosas, la desigualdad en la configuración económica de las sociedades coloniales no se da en el nivel de la circulación (en la formulación metrópoli-satélite), sino en el nivel mismo de producción y de condición heterogénea (por lo que no se puede suponer simplemente feudal) con implicaciones políticas.

El problema se entiende por la organización de la economía colonial (Sempat, 1973), generada a nivel regional como particular forma de articulación del trabajo en América Latina (en la cual no había un enclave homogeneizador) y las relaciones de poder entre actores sociales. Por lo tanto, los nudos de la formación de los Estados nacionales, a partir de las transformaciones en la producción, no se pueden sostener en la transición unilineal de feudalismo a capitalismo, sino en las disputas internas entre los actores circunscritos y en conflicto con las particulares formas administrativas de la economía colonial.

La consideración anterior representa lo que considero el punto de arribo tanto de Sempat Assadourian como de Roseberry. El primero lo expresó del siguiente modo: «Si para transformar el presente la praxis quiere reflexionar sobre sí misma tendrá que emprender otro análisis histórico: el de los grupos subalternos que desde hace algún tiempo son las clases hacedoras de la historia» (Sempat, 1973, p. 76), mientras que Roseberry, a partir de sus preguntas - desde las cuales se acercó al conflicto entre la producción comercial y el control ejercido por los hacendados-, enfatizó que:

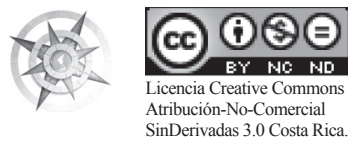


We see the importance of examinig the peasantry within haicendas, of including within the field of power the areas of strength and weakness associated with peasant livelihood (...) [This] allows us to place peasant's activities and resources at the center of our understanding of the constitution of social and political structures ${ }^{1}$ (Roseberry, 1993, p. 351).

De este modo, el nivel crítico de la cuestión paradigmática implica a su vez dos niveles: el primero abarca la interacción basada en la mercancía y la articulación de lo social asociado a la segmentación de la producción; y el segundo se refiere a la articulación de la política. Si en el primer nivel el modelo colonial de administración se basa en la heterogeneidad de formas de trabajo (que describiré más adelante a modo de nudos críticos para los casos de Ecuador y Cuba), en el segundo nivel se plantea la pregunta vinculada a la construcción del Estado a partir de las transformaciones sociales.

1 Nota de Edición: "Vemos la importancia de examinar el campesinado dentro de ciertas haciendas, de incluir, dentro del campo del poder, las areas de fortaleza y debilidad asociadas con la vida campesina (...) [Ello] nos permite ubicar las actividades y recursos del campesinado en el centro de nuestra comprensión sobre la constitución de las estructuras políticas y sociales".
Siguiendo a Sempat Assadourian (1973), en América Latina ni el mercado ni el Estado estuvieron plenamente constituidos en el siglo XIX, por lo que el vínculo fundamental en la conformación del Estado es el «lazo colonial» y no la mercancía sin más. Así, la cuestión política implica la sustitución del lazo colonial por un vínculo articulador de las diferencias, que vaya más allá de la administración de los nichos heterogéneos ejercida por instituciones coloniales. Siendo quizá más específico, Roseberry se preguntó por la formación del campesinado como clase política: «One of the effects of the study of the historical formation of particular peasantries in locally configured fields of power is that we are in much better position to ask such questions» ${ }^{2}$ (1993, p. 359). Por lo que, como resultado de la crítica (a nivel paradigmático) de estos autores, me planteo interrogantes que se traducirán en la búsqueda de las características del particular modo de producción de la hacienda colonial, así como en la indagación de las luchas políticas y la

2 Nota de Edición: "Uno de los efectos del estudio de la formación historica de ciertos campesinados en campos de poder localmente configurados, es que nos permite una mejor posición para preguntarnos sobre dichas cuestiones". 
recomposición de alianzas realizadas en medio de la heterogeneidad de los contextos coloniales.

Uno de los efectos del estudio de la formación historica de ciertos campesinados en campos de poder localmente configurados, es que nos permite una mejor posición para preguntarnos sobre dichas cuestiones.

En los nudos críticos de la formación del Estado nacional en América Latina diferenciaré dos elementos: 1) Las tensiones fundamentales en las que se involucra una diversidad de actores con intereses particulares (en este nivel me enfocaré en la transición del trabajo servil al trabajo asalariado y a las tensiones que el gradualismo generó en Ecuador y Cuba), y 2) las estrategias de negociación en las que radica el carácter paradójico de la transición de lo prenacional a lo nacional.

En La hacienda precapitalista y la clase terrateniente serrana Andrés Guerrero (1991) señaló la variedad de formas de trabajo existentes en las haciendas. Son formas de trabajo que el autor identificó como «huasipungueros, yanaperos, arrendatarios, partidarios con obligaciones de trabajo, sillajeras, peones libres y empleados» (Guerrero, 1991, p. 18). Cada uno de estos tenía una condición laboral diferente en términos de derechos y, en algunos casos, de remuneración. Es evidente que esta constatación de Guerrero da razón de la heterogeneidad estructural en los términos que indiqué, siguiendo a Sempat Assadourian.

Dichas formas de trabajo de la sierra ecuatoriana estaban ligadas a un tipo de salario en dinero a través del que se daba una apropiación de la renta. Todos los grupos anteriores recibían algún tipo de salario en dinero, aunque, como el mismo Guerrero mencionó,

Los trabajadores que vendían su fuerza de trabajo, recibiendo un salario en dinero cuyo carácter no era el de un complemento para la reproducción de su fuerza de trabajo que se realizaba gracias a otras condiciones de subsistencia, eran relativamente pocos: una ínfima minoría formada por los trabajadores calificados (que cumplían tareas específicas dentro de la división del trabajo de la hacienda como los tractoristas y algunos obreros de las lecherías o fábricas de queso), mientras que casi todos los llamados «peones libres o sueltos» eran productores inmediatos sin calificación alguna que satisfacían la necesidad de mano de obra suplementaria que implica el ciclo productivo agrícola en determinados meses del año y para ciertas tareas (1991, p. 22).

Esta introducción de la forma salario dentro del específico modo de 
producción de la hacienda huasipunguera no estuvo exenta de factores de dominación extraeconómicos. Lo que Guerrero denominó la forma huasipungo se refiere a un modo de producción en el cual los trabajadores residían en las haciendas. De este modo, la forma huasipungo

\begin{abstract}
Abastecía a la hacienda de la mayoría de productores inmediatos, los que, además, constituían el núcleo fundamental de trabajadores permanentes. Su importancia resalta aún más si notamos que esta forma implicaba la obligación de cumplir con una cantidad muy superior de jornadas (4 o 5 por semana y en algunos casos hasta 7 días) que las yanapas, partidarios y arrendatarios con obligaciones de trabajo (Guerrero, 1991, p. 22).
\end{abstract}

Esto porque lo que recibía el huasipunguero no era una remuneración a cambio de su trabajo, ya que su principal obligación era poner a disposición del terrateniente su fuerza de trabajo individual a cambio de que el hacendado le permitiera disponer de los medios de producción para su sustento.

Es a partir de este punto que el análisis de Guerrero contribuye a comprender el nudo crítico de la transición del trabajo servil al trabajo asalariado, pues se adentra en la heterogeneidad estructural que se manifiesta en la hacienda, conjugando los factores económicos, por los cuales se transforma la producción, con los factores políticos e ideológicos, por los cuales los hacendados mantienen su derecho sobre la tierra.

La introducción de la forma salario en la hacienda significó un cambio en el modo de producción que tuvo repercusiones políticas. Las modificaciones en el campoeconómico se dieron a partir de la conformación de la familia huasipungo ampliada, la cual surgió como aparato productivo debido a la inseparabilidad del trabajo necesario (para su reproducción) y el trabajo extra (para el terrateniente). Sin embargo, al tratarse no solo de un individuo (el huasipunguero), sino del trabajo de la familia, se generó un excedente que a su vez derivó en que la condición de la familia fuera: «la posesión autónoma de sus propios medios de reproducción materiales, los que permiten la realización de las diversas actividades productivas de sus miembros. La familia se apropia sin mediación alguna y por entero del producto de su actividad» (Guerrero, 1991, pp. 34-35).

No obstante, el análisis sigue ubicando este aparato productivo (la familia ampliada) dentro de los procesos de coerción ideológica y 
política, pues constituyó la mediación esencial hacia la conformación de las grandes propiedades (Guerrero, 1991). Esto llevó a Guerrero a plantear que, si bien en Ecuador no se dio un proceso de transición al trabajo asalariado, sí se inició un proceso de proletarización:

No obstante, y es un aspecto contradictorio de la forma huasipungo de trabajo tal como la vemos aquí, la familia ampliada del campesino indio no detenta más por entero todas las condiciones materiales de su reproducción. En este sentido, se encuentra ya en un proceso de proletarización y de supeditación formal a las relaciones de producción capitalistas (Guerrero, 1991, p. 42).

Sin embargo, este proceso de proletarización se dio de manera gradual, pues el paso de la producción pre-capitalista (tipificada en la hacienda) al sistema capitalista se da por la sobrepoblación de las haciendas, en las que el trabajo de la familia ampliada generaba un excedente. En el momento en el que los familiares migraron a la ciudad para vender lo que se producía en el seno de la familia se generó un proceso de proletarización informal que resultó del estancamiento de la reproducción del aparato denominado familia ampliada (Guerrero, 1991). Este estancamiento había sido producido por la decisión del hacendado de no crear más huasipungos, como expone Guerrero:

La proletarización de la familia huasipungo crea una población excedente, descampesinizada, un sector de trabajadores obligados a vender la fuerza de trabajo sin desligarse enteramente de sus raíces precapitalistas. De esta manera el hacendado encuentra las condiciones de abastecerse de fuerza de trabajo temporal por la mediación social de trabajo asalariado sin verse obligado a crear nuevos huasipungos (Guerrero, 1991, p. 60).

Así, una vez que el hacendado disponía de mano de obra temporal, su interés se desplazaba hacia la inserción de la hacienda en el modo de producción capitalista. Este cambio, aparentemente radical en cuanto a la configuración del específico modo de producción de la hacienda, revela el carácter paradójico en el que se inscriben las tensiones entre actores económicos, pues, aunque la hacienda pasó a depender tanto de un mercado nacional como internacional, esta condición no erradicó la forma de producción huasipunguera por los factores políticos que se entrecruzan.

Los factores políticos que explican, en palabras de Guerrero, «la sobrevivencia» de las formas precapitalistas de producción en el modelo capitalista se 
centran en la relación no antagónica de los hacendados (ahora acumuladores de capital global a escala nacional) con la burguesía. Sin embargo, mantener formas de producción precapitalista al interior de la hacienda fue lo que le permitió a la clase terrateniente mantener su especificidad, hasta que sus intereses pasaron a tener como centro la industria, las finanzas y el comercio (Guerrero, 1991); es decir, el nudo de la transición al trabajo asalariado se tejió en la relación entre transformaciones económicas y la conformación de sectores políticos, puesto que tal transición no se dio vía la compra de modernización para los sectores productivos, sino por medio de la paradoja fundacional sobre la que descansa la construcción de un lazo político.

Dicho de otra manera, en la economía colonial existió una diversificación de modos de producción. Se podría decir que la generación del capitalismo, como hecho económico desde la colonia, pasa por la imposición de particularismos y no de universalismos, pues los modelos administrativos insisten en la permanencia de nichos aislados de trabajo. Mark Thurner (1997) afirmó que, en la transición del Perú virreinal de la colonia al Perú poscolonial del siglo XIX, se creó una forma heterogénea de producción mediante la existencia de nichos autárquicos dentro de cada etnia. En estos nichos se asumía una exclusividad en su forma de producción como estrategia para reproducir los intereses.

El problema político se hace evidente a través de la mediación desde la que un determinado grupo o una casta con pretensiones hegemónicas hace operar la relación entre estos nichos (impidiendo así la conexción directa). Así, aunque los trabajadores serviles (i.e. en la sierra ecuatoriana) tuvieran posibilidades de cierta acumulación, estos no podían acceder al mercado. Esta inaccesibilidad al mercado, junto con otros factores, se reconoce tanto en el análisis de la hacienda de la sierra ecuatoriana (que permite ver cómo la proletarización se dio de manera gradual imbricando factores económicos y políticos) como en el caso de las haciendas azucareras en la Cuba de los años 1860-1880.

Rebecca Scott (1985) desarrolló su trabajo a partir del estudio de la abolición de la esclavitud y la transición al trabajo libre. Su tesis radica principalmente en conceder el protagonismo a los actores involucrados en un proceso que duró aproximadamente dos décadas. Se puede afirmar que Scott va más allá que Guerrero en cuanto al estudio de las dinámicas económicas y políticas, pues, al describir ambas dinámicas en un proceso de emancipación, 
relacionó los diversos actores (amos, esclavos, rebeldes y administradores) en su contexto económico colonial. En otras palabras, Scott no solo evidenció, al igual que Guerrero, la heterogeneidad estructural en el caso cubano, sino que tradujo los trabajos de Sempart Assadourian a partir de una perspectiva superadora del evolucionismo: la transformación económica por la vía revolucionaria.

Las condiciones de la hacienda azucarera que analizó Scott son diferentes a las de la hacienda huasipunguera de la que ya conocemos sus características. Así, la primera está caracterizada como sistema semimecanizado, capitalista y exportador, en la que los esclavos únicamente contaban como el factor de producción y, aunque en algunas haciendas se concedió a los esclavos partes de tierra para su autosubsistencia, estas operaban como formas de ligarlos a la plantación. Incluso los esclavos tuvieron una mínima cantidad de acumulación que les permitió participar en el sistema de coartación, que consistía en un abono sustancial que el esclavo hacía sobre su propio precio, lo que, a la vez, le atribuía una condición intermedia entre esclavo y libre. Sin embargo, para 1860 el número de «coartados» aumentó, y no así el número de libres, razón que le permitió a Scott (1985) contradecir el hecho de que después de la abolición la inserción a la sociedad estaba marcada por una movilidad social anterior.

Para Scott era importante considerar que en sus parcelas propias los esclavos recrearon su vida cultural mediante la conformación de núcleos familiares, aún en las condiciones de separatismo que caracterizaban a las haciendas. Este espacio cultural fue importante para la participación en la emancipación, pues el estudio de las condiciones de explotación permiten captar la esencia de la producción azucarera capitalista, cuyo problema de generación de capital empieza a aparecer con la disyuntiva sobre la mecanización, en el sentido de que la esclavitud requería de inversiones fijas (la manutención, por ejemplo) y reducía las posibilidades de adquirir maquinaria.

La contradicción en este modo de producción se evidencia en la medida en que, a pesar de que se podría considerar una disminución en el carácter rentable de la esclavitud, hay un aumento de la producción. A esto se añade que los aranceles fijados por Estados Unidos a la importación de azúcar, la abolición de la esclavitud en ese país, el apoyo diplomático de Cuba a la Corona española, en lo que respecta al combate del tráfico

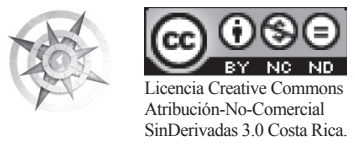


de esclavos, y el dictamen de la liberación de niños y ancianos darían forma a un nuevo escenario.

El nuevo escenario que se configura es similar, en términos generales, al que describió Guerrero en el momento de inserción de la hacienda huasipunguera en el mercado internacional. Pues, así como en la sierra ecuatoriana convivieron dentro de la hacienda las formas de producción precapitalista con la capitalista, en las haciendas azucareras de Cuba convivió la forma de explotación esclavista, aún después de la abolición declarada por la Asamblea en 1869, con la configuración del capitalismo impulsado por transformaciones politicas y administrativas que daban cuenta del papel de Cuba en la configuración geopolítica de la producción global.

Tanto en Ecuador como en Cuba el surgimiento de formas capitalistas de producción generó situaciones de ambigüedad. Por ejemplo, aunque en Cuba la Asamblea Revolucionaria decretó que todos los habitantes de la República son «enteramente libres», el proceso a continuación estuvo marcado por un Reglamento de Libertos que obligaba a estos esclavos decretados libres a seguir trabajando para sus patrones, a cambio de que estos les entregaran tierra en usufructo (Scott, 1985).
Sin embargo, una diferencia fundamental se dio en los niveles de intervención política que los grupos de poder lograron ejercer.

En Cuba, por ejemplo, existió una ley de patronato promulgada el 13 de febrero de 1880, por la cual el patrón continuaba teniendo derecho al trabajo del esclavo (ahora denominado patrocinado), a la vez que lo representaba civil y judicialmente. El esclavo tenía prohibido huir y podía ser transferido o castigado por su amo. Sin embargo, la misma ley de patronato les exigía a los patrones educar a los jóvenes patrocinados, no separar sus familias y pagar estipendios a los mayores de 18 años (Scott, 1985). De esta manera, se generó una situación intermedia entre la esclavitud y la libertad, que consistía, finalmente, en la entrega de la fuerza de trabajo de los libertos hacia los colonos en retribución por los estipendios recibidos y por su amparo y protección; mientras que en Ecuador el proceso gradual de proletarización se dio por el estancamiento del aparato productivo. Vale mencionar que en Cuba no se asoció la esclavitud y su abolición bajo la forma de guerra entre esclavos y amos, pues el deseo de emancipación se asoció con la idea de soberanía nacional, en tanto el 
gradualismo generó espacios para el uso de la ley y, con ello, la expansión del Estado (a favor de los sectores burocráticos, especialmente).

De este modo, el nudo crítico que data de la transición del trabajo servil al trabajo asalariado solo puede comprenderse en relación con otros nudos que contribuyen a historiar las dinámicas desde las que se articularon capitales de negociación de los grupos subalternos en la formación del Estado nacional.

En la formación del Estado nacional se torna necesario plantear, a modo de nudos críticos, dos procesos que repercuten en la generación de los capitales que los grupos subalternos pondrán en juego a la hora de construir un proyecto popular que, según los contextos, tendrá diferentes oponentes y estrategias que, vistas en retrospectiva, derivaron en ciertos casos en vías formales de participación política. Estos procesos están relacionados con la mercantilización de la tierra y con la articulación del campesinado y mediación institucional hacia el trabajo libre.

A partir del análisis que Barrington Moore (2002) realizó sobre el origen del Estado nacional en Inglaterra se problematiza el tema de los cercamientos como causa de la proletarización del campesinado. Para Moore esta vía sería una vía vertical por la que se llega a la construcción del Estado. Su clasificación de las vías por las cuales se arriba a la modernidad diferencia las vías democráticas (Inglaterra, Francia), fascista (Japón) y comunista (China) -aunque no por eso menos democrática-; sin embargo, su énfasis remite a que cada una de las tres vías no se configura desde quienes ostentan el poder, sino que se decide en los entornos rurales; esto significa reconocer el protagonismo de las clases agrarias y la capacidad de las élites terratenientes de dirigir el Estado en una de las tres vías mencionadas.

El factor indispensable que se desprende de Moore, y que es fundamental para América Latina, es el énfasis en las alianzas que el campesinado hizo con las élites locales (que a su vez dan sentido a la clase media). Esto implica que las clases terratenientes se transformaron en la élite burguesa (al estilo de las clases que resultaron del no-antagonismo de los hacendados y los burgueses en la economía colonial en América Latina) y que los conflictos rurales de clase son los que permiten entender la formación del Estado.

En América Latina el Estado se puede entender desde la relación entre los dos nudos crítcos que he señalado: la enajenación de la tierra 
a los campesinos (por la vía de la proletarización gradual que describió Guerrero) y su mercantilización en la emergencia de la economía nacional circunscrita al mercado global (lo cual transformó la economía colonial), con la mediación instucional que las nuevas formas republicanas jugaron en esta transición al trabajo libre a través de la formación de partidos políticos. Las relaciones entre campesinos y el sector urbano pasarían a ocupar un lugar importante en la conformación del Estado nacional en el siglo XX.

Es importante señalar que el nudo de la articulación del campesinado y la mediación institucional tuvieron distintas expresiones en América Latina. De este modo, para el caso de República Dominicana, Richard Turits (2003) analizó cómo el régimen de Trujillo (1930-1961) creó un campesinado desde un discurso nacionalista y le otorgó a la población rural un proyecto de producción, controlando la identidad y el trabajo campesino.

Turits señaló en su análisis que la creación del campesinado vía una reforma rural fue posible a partir de la institución de diferencias racistas con los habitantes de Haití, con quienes los dominicanos compartían la isla La Española. La construcción de fronteras étnicas fue indispensable para el incentivo del discurso de la identidad nacional (2003).

El proyecto de Trujillo tenía características cercanas al caudillismo, y más bien distante de un proyecto militar; sin embargo, su proyecto de «colonización del sector rural» revela el carácter ambiguo de los regímenes de proletarización del campesinado como estrategia de incorporación al Estado:

Thus under Trujillo agricultural colonies embodied a multiplicity of disparate phenomena and purposes, with a mixture of supportive and oppressive valences for residents. In some cases, colonies involved coercive elements. And in numerous instances, colonies suffered from inadequate aid, infrastructure, market access, or general agricultural conditions. But overall, colonization generated a substantial portion of the nation's crops and contributed to a political economy in which the peasantry played an important role in the nation's agricultural self-sufficiency. And although the colonies had uneven results economically, they appear to have been relatively successful in terms of regime legitimation $^{3}$ (Turits, 2003, p. 195).

A diferencia de Turits, Fernando López-Alves (2003) defendió la idea de la participación activa de distintas 
clases sociales en la conformación del Estado nacional. Para este autor se trataba de ver los distintos regímenes de clase en los que la formación de los Estados en América Latina resultó de procesos específicos, más que de la formación de las instituciones estatales. Esto permite identificar el nudo crítico que se refiere a la institucionalización de la participación y la integración de lo popular en la política.

López-Alves, en una reflexión típicamente científica, propuso varios modelos de articulación social, como tipos ideales que permiten establecer contrastes entre vías regionales de articulación de lo popular dentro

3 Nota de Edición: "Así, con Trujillo las colonias agrícolas conformaron una multiciplidad diferenciada de fenómenos y propósitos dispares, con una mezcla de apoyo y opresión combinada para los residentes. En algunos casos, las colonias incluyeron elementos coercitivos, y en numerosas ocasiones, las colonias también sufrieron de ayuda inadecuada en infraestructura, acceso a mercados y en general, de condiciones agrícolas. Sobre todo, la colonización generó una parte sustancial de las cosechas de la nación y contribuyeron a una economía política donde el campesinado jugó un importante papel en la autosuficiencia agrícola nacional. Aunque las colonias económicamente tuvieron resultados desiguales, parece que lograron un relativo exito en términos de la legitimación del régimen." del sistema político nacional (con vías paternalistas o el sistema de partidos); sin embargo, su aporte (teórico y metodológico a la vez) está en que para él la conformación del Estado: «Involucra problemas de formación de coaliciones y busca descubrir las condiciones bajo las cuales surgen sistemas más abiertos y democráticos. La construcción del Estado se relaciona directamente con las coaliciones y los tipos de regímenes» (López, 2003, pp. 25-26).

A partir de los casos de Uruguay, Colombia y Argentina, López-Alves describió la guerra como mecanismo de formación de los Estados: la incorporación de las clases populares a los ejércitos. Por lo tanto, la tesis de López-Alves es diferente a la teoría de la centralización del poder político (proveniente de Europa) como explicación de la formación de los Estados para reconocer en el conflicto político el motor de la transición. Al respecto, López-Alves afirmó que:

«...en la América Latina del siglo XIX, el conflicto surgió de las causas convencionales identificadas por muchos autores: las invasiones, la expansión territorial, la competencia por los recursos, el control del comercio nacional ó internacional, la participación en la toma de decisiones, los intereses de clase, las presiones militares y los desacuerdos en cuanto 
al diseño institucional. Este estudio, sin embargo, no es sólo acerca de la guerra, o de la noción a menudo demasiado general de "conflicto". Más bien, ofrece un argumento con bases empíricas sobre los tipos de guerra en combinación con los tipos de movilización rural, y los Estados y regímenes que surgieron como resultado (2003, pp. 27-28)»

El nudo crítico que he identificado como la institucionalización de la participación y la integración de lo popular en la política conlleva la compatibilidad con la tesis de López-Alves de que los casos latinoamericanos no pueden explicarse simplemente a partir del fracaso del sistema de partidos. Si los partidos no funcionan como tales es porque hay otras vías intermedias que articulan lo social, entre las que hay que reconocer la competencia entre las fuerzas de las que surgen formas de negociación política partidista que se debaten entre el marco institucional republicano y el discurso liberal.

\section{De los nudos críticos a las paradojas de liberalismo}

Mark Thurner (1997) aportó un modelo complejo (más ligado a la etnohistoria y la antropología) en el que la discusión señala cómo los actores que buscaban reconocimientos y derechos dentro del Estado liberal se apropiaron de instituciones sociales y jurídicas del periodo colonial. Estas demandas lograron transformar el carácter del Estado liberal por la tensión interna dentro del liberalismo, que se expresó en la voluntad que ciertos actores tenían para canalizar sus demandas. En este sentido, los grupos indígenas han orientado sus demandas hacia un concepto frágil de ciudadanía que repercute en su lucha por los derechos colectivos.

La disputa en la transición del sistema interno colonial en su forma laboral se cruzó con el elemento de la ciudadanía, y a la vez con el problema racial (Scott, 2000) y el tema del género (Mallon, 2003). Sin negar la existencia de clase, las paradojas del liberalismo estuvieron atravesadas por la tensión entre la clase social de sectores populares (y todas sus divisiones internas) y la clase de élite (que construyó un discurso científico y político). En la medida en la que el liberalismo privó de derechos colectivos y concedió derechos individuales se encontró en conflicto con derechos colectivos que habían sido reconocidos (o conquistados) desde la Colonia.

El trabajo comparativo de Scott (2000) plantea el tema de la superación que los esclavos de Loussiana (Estados Unidos) hicieron de la teoría de la supremacía racial mediante la migración a los sectores donde no había abolición de la esclavitud. Para poder mantener la mano de obra, 
los dueños de las plantaciones en Loussiana habían intentado moderar las teorías de la supremacía racial, para luego planificar el trabajo desde esta teoría dominante (mediante las líneas de color: blanco, trigreño, negro, etc.). Ese caso se contrapone al de Cuba, que en la teoría de la supremacía racial no era predominante, sino que hubo una relación híbrida, por lo que se puede decir que el hispanismo feudal entra en disputa con el significado de la integración en Hispanoamérica y las teorías de la dominación en las sociedades anglosajonas.

Rebecca Scott vió este proceso en términos de negociación cuando los grupos subalternos migraron a los lugares de trabajo libre. Es decir, mientras que en Loussiana había una construcción estatal racista, en las colonias españolas había una práctica de negociación de la frontera racial. En Cuba, particularmente, Scott (1985) evidenció cómo los esclavos (y libertos) fueron construyendo un arsenal cultural a partir de las estrategias para mantener el vínculo familiar en las haciendas azucareras, de aquí que, en la formación del Estado nacional, la manumisión fuera de la mano con la voluntad de formar parte de un discurso de una nación sin razas. Siguiendo a Guerrero (1991) y a Thurner (1997), se puede decir que en el contexto andino este poder de negociación se configuró desde la organización étnica estratégica, que les permitía a los grupos subalternos disputar las fronteras del mundo colonial. A través de este proceso los grupos subalternos de la región andina se hicieron de un capital que repercutió en la estructuración del Estado liberal.

Por otra parte, el trabajo de Florence Mallon (2003) es crucial para entender las paradojas del liberalismo, pues se enfoca en los debates en torno a la incorporación de los sectores populares en la construcción de los Estados nacionales. La autora remitió a dos casos en los que se narra el encuentro entre comunidades campesinas y Estados-nación emergentes en momentos de invasión extranjera: la intervención francesa en México y la Guerra del Pacifico en Perú. Demostró que para hacer la guerra los Estados asociados tuvieron que involucrar a las comunidades de Morelos y Puebla, en el caso de México, y de Cajamarca y Junín, en el de Perú, que, por propia decisión, se involucraron en la guerra y la política basándose en sus largas historias locales de interacción con el ámbito nacional.

El papel que tuvo el conflicto social en la inclusión de los sectores populares es la pregunta de fondo. Este problema, más específico, tiene que ver con la representación 
política desde el siglo XIX, pues en los procesos militares y guerras internacionales y civiles de esta época ya se vislumbraba el interés de las clases populares por ser incluidas.

El período del siglo XIX en el que se centró Mallon (1850-1910) se caracterizó por la fragilidad de las Repúblicas oligárquicas (posterior al período de la República de terranientes, en la que la tierra estaba ligada a la población y a un poder emparentado con las élites militares, sociedades terratenientes y caudillistas). El nudo crítico que anteriormente describí como la mercantilización de la tierra es propio de la disputa entre la perduración de sociedades terratenientes y un proceso político de descorporación de la propiedad. En esta coyuntura el Estado se declaró liberal, pero solo en cuanto a la expansión de los privilegios de una casta, y no para universalizar la ciudadanía; lo que operó en la práctica fue su contrario: el concepto de ciudadanía sirvió para quitarles la tierra, pues los derechos colectivos sobre la tierra no fueron reconocidos por la República.

Esto permite ubicar la paradoja del liberalismo en América Latina, pues se reconocían derechos individuales bajo la forma de ciudadanía y se negaban los derechos colectivos que resultaron de la acción de los grupos que, en disputa con las élites terratenientes y burguesas, consiguieron impulsar la construcción de un Estado que posteriormente los desconoció. Por lo tanto, el poder de negociación de los grupos subalternos fue puesto a prueba por un Estado que, en gran medida, incorporó sus luchas (las de los grupos de Mesoamérica, el Caribe y la región andina) y después, llegado el momento de las pretensiones de consolidación, rechazó sus intereses corporativistas. El liberalismo pretendió redistribuir el peso en la balanza del poder.

En esta paradoja los actores se posicionaron de maneras diferentes, pues estaban tanto los que retomaron el discurso colonial para plantear sus demandas (los grupos indígenas especialmente) como la nueva clase política (agroexportadora) que usó el discurso de la ciudadanía para controlar la tierra.

El tema de la declaración de la ciudadanía (en sentido formal) puede oscurecer el hecho de que en la formación de los Estados nacionales hubo grupos confrontados (de poder político y de concentración de la tierra) que daban cuenta de la existencia de la inequidad. Por ejemplo, Holt (2000) planteó que en Jamaica (luego de la emancipación en 
1838) la mayor parte de las personas trabajadoras eran mujeres, por lo que el ideal liberal impuso una lógica que suscitó un proceso de resistencia tanto de los plantacionistas como de los esclavos liberados.

Al igual que en Cuba, se instauraron formas intermedias para que los ex esclavos (que no contaban con virtudes políticas) permanecieran en las plantaciones trabajando para sus amos. Los amos no les permitían a los ex esclavos penetrar en el mercado interno para evitar que tuvieran sus propias formas de mercantilización al interior de las colonias. Al igual que el intento de la élite criolla en sudamérica, los plantacionistas de Jamaica intentaron ser los intermediarios entre los esclavos y el mercado y entre los esclavos y el Estado.

De aquí que el carácter paradójico del liberalismo se expresara en cómo los actores buscaban incorporar los derechos perdidos en el Estado liberal. El marco jurídico colonial reconocía la etnicidad (que era la forma de reconocer la situación colonial) y realizó el pacto colonial. En el reconocimiento de la etnicidad de las naciones indígenas se reconocieron también territorios. A estas naciones se les reconoció además como Estados pre-imperiales, y junto a eso hubo un reconocimiento de sus aristocracias, su organización y sus formas de trabajo, con el propósito de adaptarlas al Imperio desde los tributos. La lucha por la tierra tuvo un propósito de existencia como sujeto político, no como propietario en sentido jurídico exclusivamente.

La ficción, que ha visto este periodo como dominación sin respuesta, se contradice con la realidad de una dominación frágil, pues hay tradiciones de poder político que disputan la forma Estado.

El trabajo de Thurner (1997) y el de Alan Knight (2005) evidencian el peso que pueden tener las corporaciones indígenas en su contribución al Estado republicano, en su calidad de nuevos actores en el posible consenso. El discurso liberal, paradójicamente, les otorgó a los grupos indígenas una acumulación política que les concedía un capital que podía posicionarlos en contra de un liberalismo que confinaba las posibilidades de reconocimiento (pues no reconocía ni derechos civiles, ni políticos). De este modo, la apelación de los grupos indígenas al reconocimiento se basó en sus propios fueros y participaron en la construcción del Estado nacional no precisamente desde el discurso étnico, sino desde otros elementos (i. e. las formas particulares de justicia) que el concepto universal 
de ciudadanía ocultaba por las pretensiones políticas de las élites del poder privado republicano.

Mientras la historia europea identifica la revolución burguesa-liberal (que incluía a los ciudadanos políticamente) como antesala de una democracia gradual por la que los ciudadanos ganaron derechos sociales que compensaron las desigualdades económicas (los campesinos contra las élites), Knight (2005) planteó que el liberalismo no generó ciudadanía, puesto que los derechos políticos los tenían las minorías:

Los regímenes respondían a los temores de los blancos y mestizos a la insurgencia indígena y a la necesidad que se percibía de un sistema laboral represivo (...) la propiedad de libre mercado y las relaciones labores fueron sistemáticamente cuestionadas. Pero aparte de hacer suyas estas nuevas demandas, algunos voceros de izquierda (socialistas, comunistas, anarquistas, populistas) también declaraban que la democracia burguesa era una mera farsa y que era posible alcanzar una democracia superior, orgánica o participativa (Knight, 2005, pp. 130-132).

La democracia superior a la que se refería es precisamente aquella que se pretende como resultado de un orden político de carácter popular. Es la lucha por los derechos sociales (en un proyecto anti-oligárquico), lo que provocó en cada país la caída de los Estados oligárquicos, puesto que fueron medidos al calor de los conflictos sociales y las tensiones internas entre varios actores.

Siguiendo a Knight (2005), se puede afirmar que en América Latina la reorientación del Estado hacia la seguridad social no se dio por la vía europea del pacto capitaltrabajo (integración del trabajador al capitalismo), debido al impedimento que recaía sobre la población a la hora de entrar al ámbito mercantil. Este problema que, como he señalado anteriormente, se arrastra desde las ambigüedades de los modos de producción en la economía colonial impidió (a través de los gradualismos descritos en la sección sobre la formación del mercado como mecanismo fundamental del intercambio y de la conformación del Estado como garante efectivo de ciudadanía. Sin embargo, y a pesar de esta limitación del Estado nacional latinoamericano, el problema del reconocimiento revela, una vez más, su carácter paradójico: no hay ciudadanía, pero hay reconocimiento en cuanto a los colectivos que se encontraron organizados para plantearle al Estado sus obligaciones.

Los actores mencionados en la cita de Knight constituyeron frentes de presión social que dieron fin al Estado oligárquico y exigieron una

\section{Nudos críticos, paradojas y hegemonía... Jorge Daniel Vásquez-Arreaga}


incorporación de lo popular dentro de la política, bajo el discurso de la demanda de derechos sociales y el discurso de clase. A través de estos discursos se configuró el proceso de interpelación del Estado y la exigencia de derechos políticos ante una ciudadanía que se presentaba excluyente. De este modo, se puede decir que la identidad en la especificidad fue una forma de integrar a los actores al Estado y que la ciudadanía, en clave popular, se entendía como las bases organizadas desde las que se conformaron los discursos sobre derechos.

Por lo tanto, la entrada de lo popular en lo político no se dio en condiciones de ciudadanía liberal, sino en la constante configuración del Estado nacional, atravesada por la entrada de actores colectivos que se identificaron como clase. El discurso de clase ofreció posibilidades para abarcar aquellos discursos que podían plantearse desde la etnicidad o específicamente desde lo nacionalpopular. En esta medida, constituyó el elemento desde el cual los actores sociales se posicionaron en la paradoja del liberalismo en América Latina.

\section{Diferentes vías en la formación del Estado: negociación y hegemonía}

Algunos elementos sobre la relación entre conflicto y hegemonía en la construcción del terreno político han sido mencionados en los apartados anteriores: las formas en las que las clases terratenientes, con fines hegemónicos, promovieron la diversificación de formas de trabajo asalariado en las haciendas para disuadir el conflicto con los grupos de trabajadores, el establecimiento de formas graduales lideradas por una clase política que generaró situaciones ambiguas en los sectores emancipados en las sociedades esclavistas, el establecimiento de instancias de mediación entre el mercado y las haciendas para dilatar el conflicto social con los grupos subalternos en su disputa por incorporarse al mercado nacional y, finalmente, el uso hegemónico de la categoría de ciudadanía como un monotema abstracto que privilegiaba solo a las élites republicanas ante las demandas de los sectores populares.

Cuando realicé la lectura de Sempart Assadourian (1973) señalé que las sociedades latinoamericanas no tendían a la proletarización (como lo plantea el marxismo), sino que el proletariado, por las condiciones de producción de América Latina, era de carácter heterogéneo. Así, la tendencia de la estructura social no era la simplificación, por lo que resultaba necesario evaluar la capacidad explicativa del marxismo ortodoxo (que sostenía un enfrentamiento total entre burguesía y proletariado). En este 
contexto, el concepto de hegemonía resulta pertinente para la articulación política de la heterogeneidad. Esta articulación se puede dar por la vía burocrática-corporativa o por la vía de la hegemonía. Si en la década de los setenta se desarrolló el concepto de heterogeneidad estructural, la propuesta de Gramsci a través de su categoría de hegemonía propone entender el surgimiento del carácter emancipatorio.

Plantear el asunto de la hegemonía en la formación de los Estados nacionales en América Latina implica asumir que existe un conflicto en la misma conformación de la política. Por lo tanto, siguiendo principalmente el estudio de Florence Mallon (2002) y el de Alan Knight (2002), se puede evidenciar cómo la construcción de la hegemonía remite a procesos por medio de los cuales en el México del siglo XIX los sectores sociales aprendieron a traducir las diferencias internas y cómo estas pasaban de la dinámica interna del movimiento a una articulación a nivel nacional. En contraste (es decir, como una vía no-hegemónica), se encuentra el caso de República Dominicana (Turits, 2003) y el de Perú (también recogido en el texto de Mallon, 2002).

Al hablar sobre la articulación del campesinado y las mediaciones institucionales he mencionado el caso de
República Dominicana. Sin embargo, ahora quisiera señalar que los factores que Turits (2003) recogió sobre la formación del Estado dominicano dan cuenta de una dominación sin hegemonía. El autor se enfocó en el boicot que experimentó Haití por parte del sistema internacional luego de su emancipación, en la fundación de la República negra y en el caso de Trujillo en la isla La Española, que fue un sistema de integración autoritaria. Los dominicanos construyeron su identidad dominicana a partir de un proceso de imposición. Ante la negativa de otras alternativas de identificación, el discurso nacionalista no se fundó en consenso alguno, sino en el terror al poder militar, en un proceso que ligó intenciones productivas con los fines políticos en tres momentos:

1. la producción de una sociedad transfronteriza y un sector no integrado,

2. un proceso trujillano de asignación de tierras para generar campesinado $y$

3. la creación de una identidad anti-haitiana. Este proceso permite reconocer una identidad (e incluso una legitimidad conquistada por el Estado), pero no un proceso hegemónico.
76 Nudos críticos, paradojas y hegemonía... Jorge Daniel Vásquez-Arreaga 
A diferencia de lo acontecido en República Dominicana, Mallon planteó que en la Sierra de Puebla, en México, «la política local y las instituciones comunales eran campos de intereses en los que el poder se negoció y acumuló a lo largo del periodo colonial y hasta entrado el siglo XIX» (2002, p. 126). Esta forma de política local repercutió significativamente, hacia 1940, en la construcción de un Estado «eficaz y hegemónico» (p. 142).

En la negociación se puede reconocer que el conflicto de poder se construyó en términos diversos cuando de disputas hegemónicas se trata. Por ejemplo, Tourits (2003) describió rutas alternas para la distribución del poder entre distintos grupos etáreos (entre ellas la milicia). Ante la jerarquía civil-religiosa que concedía los cargos principales a los ancianos (los pasados), la milicia les brindaba una alternativa a los indios jóvenes, pues permitía pactar con funcionarios españoles y pasar por alto la autoridad generacional y patriarcal. Del mismo modo aconteció con el surgimiento de los municipios que les dieron a los más jóvenes una fuente diferente de poder a nivel local.

Para Mallon, el México decimonónico fue un claro caso de hegemonía comunal. Esta constituye un tipo de liderazgo que construye lo nacional y que se traduce en formas de organización política como las asambleas: «Esos conflictos y divisiones podían resolverse en las asambleas comunales, que eran la arena cuidadosamente construida donde se dirimía el discurso comunal y donde los diferentes grupos de interés, facciones o individuos buscaban la aprobación colectiva de sus proyectos o su estatus» (Mallon, 2002, p. 128).

La cita contribuye a la identificación de la hegemonía comunal como una categoría traducida en procesos de diferenciación de los actores. La tarea de pensar las diferencias, las jerarquías y los poderes en espacios en los que se pueda dar cuenta de procesos hegemónicos al interior de los espacios comunitarios.

La hegemonía comunal en México permitió ver un estilo de liderazgo y unas formas de construir el poder político entre generaciones que se modificó sustancialmente, pues «si la hegemonía comunal estaba organizada internamente en torno de un concepto de justicia generacional y de género, era igualmente importante para su reproducción cabal la forma que adoptaran las relaciones con la sociedad y la economía en general» (Mallon, 2002, p. 130).

La hegemonía así descrita contribuyó a la formación de la cultura política

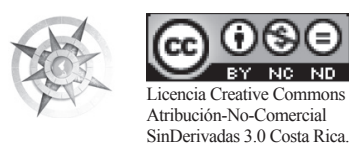


comunal y de un patriarcado que, aún con ciertos signos democráticos, sirvió para que durante la revolución de 1910 se ejerciera un control patriarcal del Estado (Mallon, 2002).

Las estrategias de negociación establecidas por los actores sociales lograron plantear los conflictos políticos en términos de hegemonía, en un sentido gramsciano. Esto no se desliga del hecho de que en América Latina el capitalismo se construyó en una situación colonial y de que la política se fundó en el conflicto colonial. Se puede decir que el subalterno se experimenta en medio de una sociedad conflictiva colonial, pero que, en la disputa por los liderazgos y los establecimientos de pactos políticos (con caudillos, militares u otros sectores), la historia política de América Latina permite hablar de un sujeto colonial que surgió de este conflicto, al mismo tiempo que buscó reconocimiento en las instituciones políticas. En esto último se diferencia de el proletario, pues este no buscó reconocimiento en instituciones políticas).

El análisis de Mallon contrapone el caso de México al caso del Perú. Este último, al igual que República Dominicana, se construyó heterónomamente en una operación vertical encabezada por el Estado. La sociedad oligárquica del Perú desenvolvió prácticas de represión en alianza con los partidos. Mallon consideró que «el moderno estado peruano (...) se construyó a través de una serie de negociaciones zigzagueantes entre esos contradictorios creadores de progreso y amiguismo, modernización y represión» (2002, p. 140), a través de una alianza entre los partidos y la clase hacendaria. Por eso, las formas de establecimiento de los pactos políticos hicieron que la formación del Estado nacional en México difiriera sustancialmente de la formación del Estado peruano o del dominicano.

Alan Knigth planteó la hegemonía en dos momentos. El primer momento: en su trabajo «Armas y arcos en el paisaje revolucionario mexicano» (2002), en el cual se describen las estrategias hegemónicas y los factores que llevaron a que la Revolución en México no se diera con la misma intensidad en todo el país. Según su análisis, la región de Sedeka es un lugar en el que la postura antirevolucionaria se explica por la convergencia de empresas extranjeras empleadoras del campesinado, el contrato entre campesinos y élites y el papel de la Iglesia Católica. Los tres factores son reproducidos y construidos hegemónicamente desde la voluntad particular de las élites. 
En un segundo momento se encuentra el texto Revolución, democracia y populismo en América Latina (2005), en el cual se describe cómo el partido PNR/PRM/PRI fue precedido y engendrado por la Revolución. El caso del PNR/PRM/PRI fue un caso de hegemonía, en tanto pretendió abarcar en un proyecto estatal todas las demandas de los sectores populares que hicieron la Revolución. Esto último evidencia que, precisamente, el proyecto hegemónico se afianza en cuanto mantiene su capacidad de leer cuál es el consenso fundamental sobre el que se puede mantener el poder y luego establecer un liderazgo moral que genere un discurso nacional basado en la experiencia política.

\section{Referencias bibliográficas}

Barrington, J. (2002). Los orígenes sociales de la dictadura y de la democracia. Barcelona, España: Península.

Guerrero, A. (1991). La hacienda precapitalista y la clase terrateniente serrana. En A., Guerrero, De la Economía a las Mentalidades (Cambio social y conflicto agrario en Ecuador) (pp. 11-76). Quito, Ecuador: El Conejo.

Gunter Frank, A. (1965). Capitalismo y subdesarrollo en América Latina. Texto completo en: http://www.eumed. net/cursecon/textos/
Holt, T. (2000). The Essence of the Contract. The Articulation of Race, Gender, and Political Economy in British Emancipation Policy, 1838-1866. En F., Cooper, T., Holt, \& R., Scott, Beyond Slavery. Explorations of Race, Labor, and Citizenship in Postemancipation Societies (pp. 33-60). Chapel Hill, USA: The University of North Carolina Press.

Knight, A. (2002). Armas y Arcos en el paisaje revolucionario mexicano. En G., Joseph \& D., Nugent (comp.), Aspectos cotidianos de la formación del estado. La revolución y la negociación del mando en el México moderno (pp. 53-101). México: Era.

Knight, A. (2005). Revolución, democracia y populismo en América Latina. Santiago, Chile: Centro de Estudios Bicentenario.

López, F. (2003). La formación del Estado y la democracia en América Latina 1830-1910. Bogotá, Colombia: Norma.

Mallon, F. (2002). Reflexiones sobre las ruinas: formas cotidianas de formación del Estado en el México decimonónico. En G., Joseph \& D., Nugent (comp.), Aspectos cotidianos de la formación del estado. La revolución y la negociación del mando en el México moderno (pp. 105-142). México: Era.

Mallon, F. (2003). Campesino y nación: la construcción de México y Perú poscoloniales. México: CIESAS.

Roseberry, W. (1993). Beyond the Agrarian Question in Latin America. En F., Cooper, A. F., Isaacman, F. C., Mallon, W., Roseberry \& S., Stern, Confronting Historial Paradigms (pp. 318-368). Madison, USA: The University of Wisconsin Press. 
Sempat, C. (1973). Modos de producción, capitalismo y subdesarrollo en América Latina. En VV.AA., Modos de producción en América Latina (pp. 47-81). Buenos Aires, Argentina: Ediciones Pasado y Presente.

Scott, R. (1985). Slave Emancipation in Cuba. The Transition to Free Labor 1860-1899. Princeton, USA: Princeton University Press.

Scott, R. (2000). Fault Lines, Color Lines, and Party Lines. En F., Cooper, T., Holt \& R., Scott, Beyond Slavery. Explorations of Race, Labor, and Citizenship in Postemancipation Societies (pp. 61-106). Chapel Hill, USA: The University of North Caroline Press.

Thurner, M. (1997). From two republics to one divided: contradictions of postcolonial nation making in Andean Peru. Durham, USA: Duke Universtiy Press.

Turits, R. (2003). Foundations of Despotism. Stanford, USA: Stanford University Press. 